\title{
Historia
}

\section{Barberos y Sangradores en Iberoamérica ${ }^{1}$}

\section{Barbers and Bleeders in Latin America.}

\section{Barbeiros e Sangradores Iberoamericanos.}

\author{
Raúl Expósito González
}

Enfermero. Hospital General Universitario de Ciudad Real

'El contenido de este trabajo se presentó en forma de comunicación oral en el IX Congreso Nacional y IV Congreso Internacional de Historia de la Enfermería celebrado en Las Palmas de Gran Canaria los días 26, 27 y 28 de abril del año 2007.

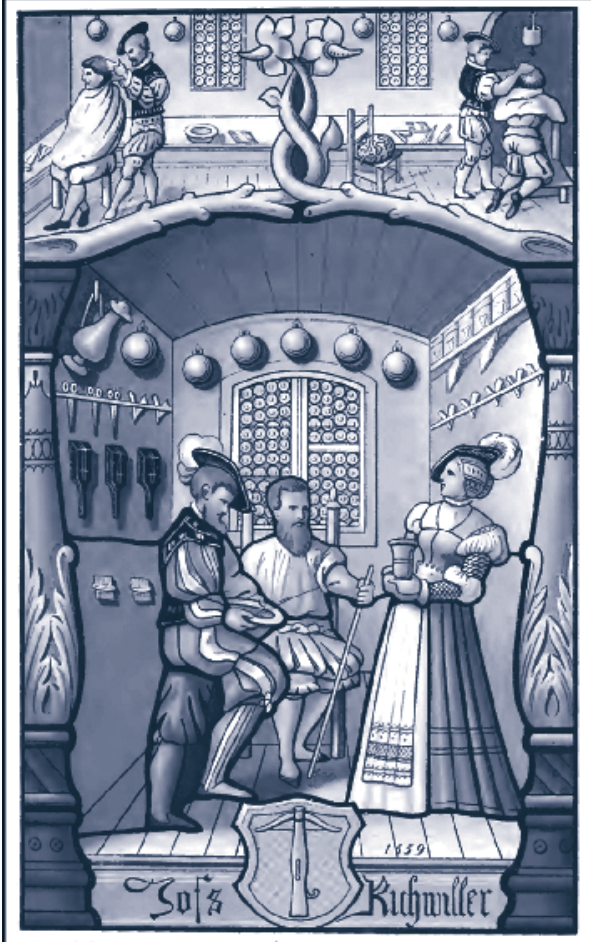

\section{Barbers and Bleeders in Latin America}

\section{ABSTRACT}

The discovery of the New World brought a series of profound changes and transformations in the habits and lifestyles of indigenous peoples, not only in terms of political, econo- mic social and new civilizations, but also in the field of science, as Medicine and the different branches of the healing art, being a clear example in this sense the arrival of barbers and bleeders from the Iberian Peninsula.

Key words: Barbers, Bleeders, Phlebotomy, Latin America.

\section{Barbeiros e Sangradores Iberoamericanos}

\section{RESUMO}

O descobrimento do Novo Mundo trouxe consigo uma série de profundas mudanças e transformações nos costumes e estilos de vida indígenas, não somente em relação à organização política, social e econômica das novas civilizações, mas também no campo das ciências, como a Medicina e as distintas especialidades da arte da cura, destacando-se, como um expoente claro, a chegada de barbeiros e sangradores, procedentes da Península Ibérica.

Palavras chave: Barbeiros, Sangradores, Flebotomia, Ibero América.

\section{RESUMEN}

El descubrimiento del Nuevo Mundo trajo consigo una serie de profundos cambios y 
transformaciones en las costumbres y estilos de vida indígenas, no sólo en cuanto a la organización política, social y económica de las nuevas civilizaciones, sino también en el campo de las ciencias, como la Medicina y las distintas ramas del arte de curar, siendo un exponente claro en este sentido la llegada de barberos y sangradores procedentes de la Península Ibérica.

Palabras clave: Barberos, Sangradores, Flebotomía, Iberoamérica.

\section{INTRODUCCIÓN.}

La llegada de los españoles a América y la posterior colonización de estos territorios conllevó una serie de intensos cambios en las costumbres y estilos de vida de los aborígenes con la implantación de un nuevo ordenamiento que afectaría no sólo a la vida política, social y económica de los nuevos asentamientos sino que también afectaría al ámbito de la sanidad. En este sentido, barberos y sangradores procedentes de la Península Ibérica arribaron al Nuevo Mundo para desarrollar el oficio que hasta entonces venían desempeñando en España, las operaciones de cirugía menor, y en diversas situaciones otras de distinta envergadura, hasta el punto de convertirse en muchas ocasiones en el único referente al que acudir en caso de enfermedad.

En la bibliografía sobre la historia de las distintas ramas del arte de curar y de cuidar generada en nuestro país, así como recientemente en otros de habla hispana, podemos encontrar referencias claras y alusiones a las actividades de estos barberos y sangradores.

Pretendemos por tanto, mediante la revisión de estas fuentes junto con la de otras ya clásicas conocer aún más de cerca el oficio artesanal de los barberos y sangradores y su repercusión en la nueva sanidad que se iba gestando en Iberoamérica y en la que estos empíricos al igual que había sucedido anteriormente en la Península, tampoco estuvieron exentos de disputas y pleitos con los escasos médicos y cirujanos que trataban de abrirse camino en América.

\section{PRÁCTICAS MÉDICAS EN AMÉRICA ANTES DEL DESCUBRIMIENTO.}

Aunque no es objeto de este estudio ya que merecería un trabajo exclusivo, sí que es necesario resaltar de manera esquemática algunas de las nociones curativas contra la enfermedad que los indios del centro de América y de los Andes tenían mucho antes de la llegada de los primeros europeos al continente:

\section{Aztecas:}

- Conocían y aprovechaban las propiedades curativas de las hierbas medicinales.

- Tenían parteras, "tlamatquiticitl”, para la instrucción prenatal y postnatal así como para asistir a los partos.

- No permitían ejercer la medicina sin aprobar un examen de competencia.

- Practicaban la sangría.

- Seguían el método experimental.

- Eran hábiles cirujanos: utilizaban el bisturí de obsidiana, trepanaban cráneos, realizaban incrustaciones dentarias y sabían tratar luxaciones, fracturas, quemaduras, úlceras...

- Conocían la utilidad de la hidroterapia.

- Ejercían en grandes establecimientos hospitalarios para indigentes a modo de hospicios.

\section{Incas:}

- Empleaban purgantes, sangrías y drásticos.

- Conocían las propiedades diuréticas del maíz y las propiedades febrífugas de la quinina o cascarilla de Loja. 
- Practicaban la hidroterapia mediante "temazcallis" o sudatorios.

- Practicaban la trepanación.

- Cuidaban su higiene y el "armacuni" o baño diario.

- Eran importantes los baños termales para enfermedades de la piel.

- Impregnaban sus flechas clavándolas en cadáveres en avanzado estado de putrefacción lo que evidencia sus conocimientos acerca del valor tóxico de las ptomaínas cadavéricas.

- Desconocían el valor del pulso y tomaban la temperatura entre las cejas, a la altura de la base de la nariz.

En Perú, cuna del Imperio Inca, el ejercicio de la medicina estaba a cargo de los sacerdotes, "amautas", dedicados al tratamiento de reyes, caciques, parientes y eclesiásticos, mientras que la gente del pueblo, transmitía de padres a hijos los conocimientos médicos, sin rendir ningún examen y sin criterio experimental.

\section{Araucanos:}

Poseían tres clases de médicos:

- "Ampives”, que eran herboristas

- "Vilens", versados en parasitología.

- "Machis", que eran hechiceros y exorcistas.

\section{Charrúas:}

El remedio universal a todos sus males consistía en chupar con fuerza el estómago del paciente para sacar el mal.

\section{Guanas:}

También curaban como los charrúas solo que la profesión estaba monopolizada por mujeres ancianas.

\section{Minuanes:}

Curaban a sus enfermos chupándoles el es- tómago con la particularidad de que la medicina era ejercida tanto por hombres como por mujeres.

\section{Guaraníes:}

Ayunaban durante el embarazo.

\section{Tobas:}

Ingerían el banga para evitar los vómitos incoercibles.

\section{Aborígenes del Chaco: \\ No comían carne.}

La mayoría de estos remedios contra la enfermedad como hemos mencionado anteriormente, venían siendo utilizados por los indios de forma milenaria y gran parte de ellos eran acompañados de un componente religioso, de manera que eran practicados como si de un ritual mágico se tratase en los cuales eran invocados sus Dioses de la Salud y la Enfermedad y; no deja de ser llamativo el ver cómo eran conocedores de ciertos tratamientos como la célebre sangría, que en Europa había adquirido gran prestigio sobre todo en la Edad Media.

\section{LOS BARBEROS EN EL MEDIEVO Y EN LA EDAD MODERNA.}

A lo largo de las diferentes etapas históricas podemos encontrar leyes y disposiciones relativas al ejercicio profesional de los barberos. En el Fuero Juzgo, cuerpo legislativo que rigió en la Península Ibérica durante la dominación visigoda de Hispania, aparece el término sangrador. Éste no debía sangrar a ninguna mujer sin que sus parientes estuviesen delante. En la Corona de Castilla, el Fuero Real de 1225 estableció una distinción entre médicos o "físicos" y cirujanos o "maestros de llagas", dictándose algunos años después, las normas para el ejer- 
cicio de los barberos, mediante el Código de Las Siete Partidas de Alfonso X "El Sabio". Según este código los barberos o "alfagemes" debían afeitar en lugares apartados y no plazas y calles, con penas para aquellos que embriagados o sin conocimiento del oficio ocasionasen la muerte al afeitar o sangrar.

La separación de la Medicina y de la Cirugía era patente. Incluso había diferencias entre quiénes ejercían el oficio quirúrgico. Así, en el siglo XIII existían en la Corona de Aragón los médicos no cirujanos o "metges de física", los médicos cirujanos o "metges de cirugía", también llamados "cirurgians de roba llarga" y los "cirurgians de roba corta" o cirujanos barberos y sangradores que quedaban relegados a las cirugías menores tales como sacar muelas, poner ventosas, realizar sangrías... que venían siendo desempañadas por los barberos en la Península Ibérica desde antes de la cristiandad.

Durante la Edad Media los gremios y cofradías desempeñaron un importante papel. El movimiento gremial no sólo afectó a las asociaciones de artesanos, sino también a las cofradías de otras profesiones liberales. Así, a partir del siglo XIV se fundaron las primeras Cofradías
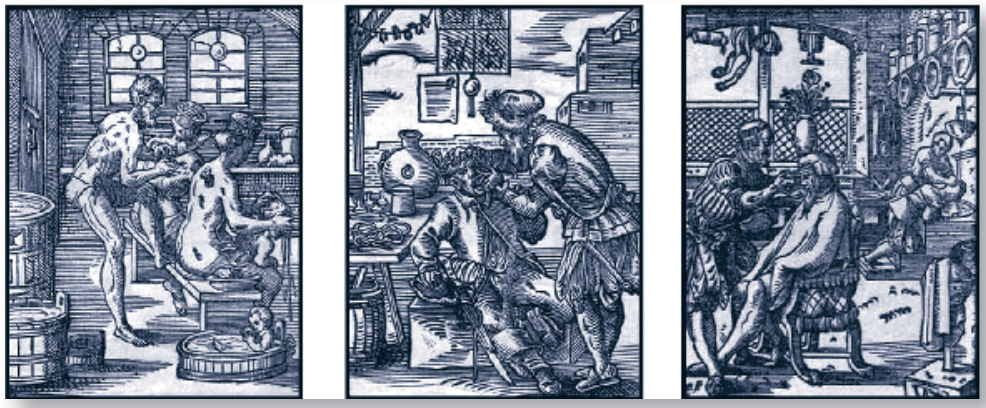

Los barberos rapaban las barbas y si además eran aprobados por el Protobarberato tenían licencia para sajar, sangrar, aplicar ventosas y sanguijuelas y sacar dientes y muelas. (Grabados de Jost Amman, año 1568). nal del Protomedicato de Castilla durante el reinado de los Reyes Católicos supuso un importante avance para la regulación y el ordenamiento de las profesiones sanitarias, incluidos barberos y sangradores, que eran examinados en un principio por el Protobarberato, tribunal destinado para tal efecto [1].

Los Reyes Católicos en abril de 1500 por medio de una Ley Pragmática regularon las tareas y exámenes de los llamados "barberos flomotomianos":

"Mandamos que los Barberos, i Exâminadores Mayores de aquí adelante no consientan, ni dèn lugar que ningún barbero, ni otra persona alguna pueda poner tienda para saxar, ni sangrar, ni echar sanguijuelas, ni ventosas, ni sacar dientes, ni muelas, sin ser exâminado primeramente por los dichos nuestros Barberos Mayores...". de Barberos y Cirujanos

bajo la advocación de los Santos Patronos San Cosme y San Damián que eran instituciones de carácter religioso y benéfico aunque en sus Estatutos se dictaron normas sobre el ejercicio profesional. No en vano, para poder ejercer los cirujanos-barberos debían ser examinados por dos cirujanos de la cofradía.

En el siglo XV, la creación del Real Tribu-
Claramente se establece la separación entre el oficio barberil y el de la flebotomía (sangría) y demás operaciones de la cirugía menor:

“...qualquiera, que quisiere, pueda afeitar de nabaja, ò de tixera, sin ser exâminado, i sin su licencia: pero mandamos que no pueda usar, ni use el Arte de la Flomotomia, ni sangrar, ni saxar, ni sacar diente, ni muela, sin ser exâminado como dicho es...". 
Esta ley, así mismo, fijaba duras sanciones para aquellos que contraviniesen lo sancionado por sus majestades Isabel y Fernando:

"...qualquiera que usare de las cosas susodichas, ò de qualquier dellas, sin ser exâminado como dicho es, sea inhabil perpetuamente para usar del dicho oficio, i mas pague dos mil maravedís de pena para la nuestra Camara, i mil maravedís para los dichos nuestros Barberos Mayores; $i$ por el mismo hecho aya perdido, $i$ pierda la tienda, que assi tuviere puesta...”.

El aprendizaje de los futuros barberos comenzaba normalmente a la edad de 16 años, frecuentemente continuando con una tradición familiar, aprendiendo de sus padres o tíos (maestros examinados), los cuales ya estaban establecidos pero no siempre era así, pues muchas veces el aprendiz se colocaba en casa ajena, y era entonces cuando ambas partes formalizaban un contrato ante notario, por el que se comprometían maestro y aprendiz a una serie de derechos y obligaciones. El aspirante aprendería el arte de sangrador flebotomiano por espacio de cuatro años y a este contrato se le conocía como "carta de asiento", "asiento de aprendiz" o "contrato de aprendizaje" (Martín Santos, 2000) que consistía en:

- El padre del aprendiz pagaba al barbero por esta enseñanza, para vestir a su hijo y para todo lo referente al oficio (tijeras y demás instrumental).

- El barbero se comprometía a enseñar el oficio, dar de comer, cama y ropa limpia al aprendiz, así como curar si este cayese enfermo durante los primeros ocho días, después, si continuase enfermo, correría por cuenta de su padre.

Al final, como parte del contrato, el maestro suministraba el instrumental necesario para el ejercicio autónomo del oficio por parte del nuevo barbero que consistía en:
"Un herramental de ofiçio en que aya quatro navajas e un par de tiseras e una piedra e dos lançetas [para sangrar] e un espejo e dos peynes todo bueno de dar e de tomar" (García Ballester, 2001).

Para poder acceder al examen los aspirantes al título de barbero debían reunir una serie de requisitos tales como:

- Probar la limpieza de sangre y certificado de buena conducta alusiva a la moral [2].

- Certificados de haber realizado prácticas indicando lugares, maestros y duración. Estos iban firmados por los alcaldes o corregidores de las villas y refrendados por los maestros y testigos.

- Una vez aceptadas las candidaturas se señalaba el día y hora de examen. Aprobado el examen teórico acerca del conocimiento de las venas, cuáles y cuántas son, y en qué lugares se reparten y de los nombres de ellas y del modo de sangrar, sajar y echar ventosas y sanguijuelas $y$ sacar dientes y muelas y otras preguntas tocantes a dicho arte, se emplazaba a otro día para realizar el práctico en un hospital público ante notario y testigos presentes. Demostrada la habilidad y suficiencia del aspirante, se concedía "carta de examen y licencia para poner tienda" $\mathrm{y}$ practicar el arte de la flebotomía en todas las ciudades, villas y lugares del reino y señoríos de su majestad, previo juramento de practicar el arte "bien y fielmente" $y$ "asistir a los pobres de limosnas".

- Así mismo, se abstendrían de sangrar y sajar sin licencia y mandato de un físico o cirujano, salvo en los casos de "esquinancia, caída o dolor de costado".

Los derechos de examen se fijaban en media anata, que era el equivalente a la mitad de 
los emolumentos que podía producir el empleo en un año (Amezcua Martínez, 1997).

Tras obtener "carta de examen" lo nuevos barberos podían poner tienda pública o barbería que era lo más frecuente, bien sólo o con otro colega y compartir gastos y beneficios o; concertarse con algún hospital o con uno o varios pueblos - el salario normal del barberocirujano se situaba entre 5000 y 10000 maravedís (Rojo Vega, 1993) - y con mucha suerte, servir en casa de algún noble adinerado (Martín Santos, 2000).

También era habitual desde varios siglos atrás, la presencia de barberos en las expediciones a bordo de las galeras, donde fueron de gran ayuda en el tratamiento de las heridas y enfermedades de las gentes del mar (Cifuentes i Comamala, 2000).

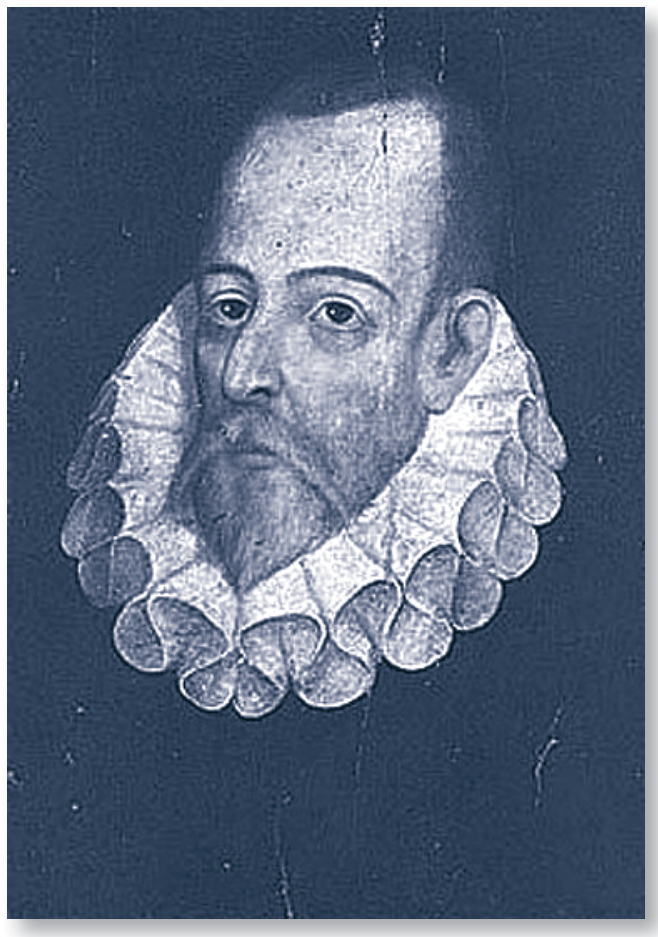

Miguel de Cervantes, el más grande escritor de todos los tiempos era hijo del barbero Rodrigo de Cervantes. (Retrato atribuido a Juan de Jáuregui, año 1600).

\section{LA TIENDA O BARBERÍA.}

La tienda o barbería normalmente solía estar en el portal de una casa, que generalmente era en la que vivía el barbero, y sus reclamos eran la "bacenica" o palangana y la celosía o reja (López Acuña, 1952). Dentro de la tienda había bancos de madera para los clientes que esperaban su turno además de las "sillas del oficio" en la que se afeitaba y se sajaba, además del "cajón de tienda" que guardaba paños y lienzos, cajitas, estuches, lanceteros y bolsas, donde se metían polvos, agujas, lancetas, hierbas... y los arcos que custodiaban los "lienzos del oficio" y la "caja de hierro" donde se recaudaba el dinero diario.

Las herramientas o instrumental de una barbería podían ser de varios tipos:

1. De barbería, tales como navajas, tijeras, peines, bacines y bacías que eran las vasijas que usaban los barberos para remojar la barba, con una escotadura semicircular en el borde. En la Edad Media eran redondas y en el siglo XVI de forma oval. En el siglo XVII pasaron a ser la enseña de los barberos y cirujanos, distinguiéndose sólo en que la de los primeros era blanca y la de los segundos amarilla. Se fabricaron de loza en el siglo XI, decoradas con figuras y adornos, siendo las más afamadas las de Talavera de la Reina. La bacía del barbero quedará inmortalizada por Cervantes en su obra universal El Ingenioso Hidalgo Don Quijote de La Mancha con el nombre del yelmo de Mambrino.

2. De cirugía, tales como jeringas y jeringuillas para lavativas; lancetas en sus tres variantes: grano de cebada (más apropiada para principiantes), lengua de serpiente y grano de avena; ventosas y sajadores para sangrar; medicamentos como tópicos y 
ungüentos y; demás instrumental para otras intervenciones como pinzas, apostemeros y embudos-sonda.

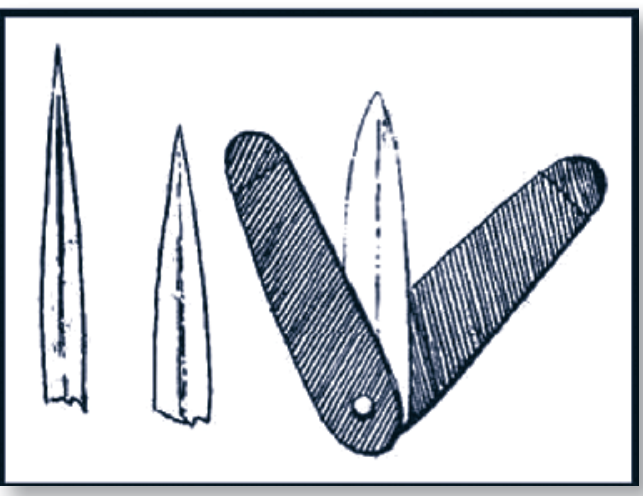

Diferentes tipos de lancetas. De izquierda a derecha: grano de cebada, lengua de serpiente o piramidal y grano de avena.

3. De odontología, para la extracción de piezas dentarias como el pulicán para sacar muelas muy dañadas y raigones; alicates para dientes sueltos y raíces muy superficiales; dentuza para caninos e incisivos; gatillo y gatilla para muelas pequeñas $\mathrm{y}$; el descarnador, para separar el diente de la parte de encía que hay a su alrededor. Para la conservación de muelas y dientes se hacían cauterios con fuego y oro.
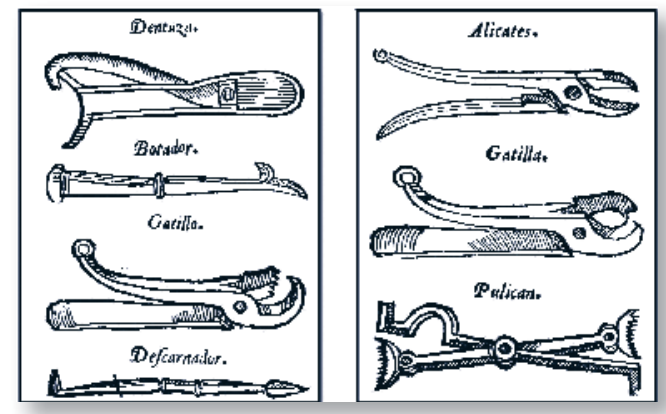

Hierros empleados por los barberos para sacar dientes $y$ muelas.

\section{LA LLEGADA DE LOS BARBEROS ESPAÑOLES A AMÉRICA.}

Hasta ahora hemos definido de manera resumida el oficio barberil y su regulación en España durante la Edad Media y principios de la Edad Moderna. Muchos de estos barberos, tal vez movidos por el afán de ganarse un prestigio o simplemente huyendo de un mundo en el que no tenían cabida por no reunir las condiciones exigidas para revalidar el título ante el Protobarberato, decidieron partir y probar suerte en el Nuevo Mundo [3]. Cuando Hernán Cortés se embarcó para Veracruz, trajo consigo a dos de estos truhanes, Juan el Catalán y Juan de Murcia, los cuales se instalaron y llevaron a cabo sus actividades dentro de las huestes colonizadoras de la Nueva España, ocasionando innumerables problemas.

Los barberos flomotomianos, flebotomianos, flebotomistas o sangradores sobrevivirían casi cuatro siglos en la Península y en el Nuevo Continente acompañando a Colón en la aventura transoceánica como Maese Juan Sánchez, cirujano a bordo del primer viaje del descubridor a América y que quedó en La Española (Eseverri Chaverri, 1995). Desde entonces y por mucho tiempo, los que más llegaron para quedarse eran barberos. Del segundo viaje desembarcaron entre otros el barbero Melchor, y en 1519 Magallanes traía a bordo tres barberos.

Como se puede comprobar existía un predominio de los barberos sobre médicos y cirujanos en los primeros pobladores de América según el Índice Geobiográfico de Boyd-Bowman (Saturno Canelón, 1996):

- 1493-1519: 13 barberos, 8 cirujanos y 4 médicos.

- 1520-1539: 13 barberos, 9 cirujanos y 9 médicos. 
VI. LOS BARBEROS Y EL NUEVO ORDENAMIENTO: EL PROTOMEDICATO DE INDIAS.

La práctica médica en los primeros años de presencia española en América dependió de Cabildos y Audiencias hasta la creación del Protomedicato de Indias en 1570. La asistencia sanitaria durante este periodo estuvo marcada por la fundación de gran número de hospitales y la escasez de facultativos, contrarrestada de manera alguna por los barberos que atendían a las necesidades más inmediatas con recursos traídos de la Península o con los asimilados de los aborígenes, aplicando destrezas quirúrgicas que dominaban y formando al nuevo personal en un conocimiento tan mestizo como sus alumnos, en el que la mayoría de los barberos eran nativos, y su diferencia con los médicos no estaba en la longitud de sus batas, sino que radicaba en el color de la piel (los pocos médicos de los siglos XVI y XVII eran blancos). La sangría la aprendieron de los barberos hispanos, ya que lo que antes practicaban los incas y aborígenes de toda la selva tropical americana, era la escarificación y posterior succión de las superficies escarificadas. competencias sobre el examen de físicos, cirujanos, boticarios y flebotomianos y parteras, además de preparar informes en casos de epidemias, pero sobre todo incidió en el control de las boticas.

Instalado el Protomedicato en las Indias los requisitos para obtener la licencia de barbero no era muy distinto al modelo español (Lanning, 1997):

- Certificado de bautismo que probara la legitimidad o "limpieza de sangre": debía ser hijo de "viejos cristianos", "libres de toda mala raza de moros, indios y otros".

- Probar haber servido tres años como aprendiz en un hospital o cuatro con cirujano o flebotomiano aprobado.

- Examen oral, por lo que podían pasar las pruebas sin leer ni escribir. Naturalmente el conocimiento de venas y arterias era fundamental si el sangrador quería evitar tragedias. Más allá de este conocimiento elemental, debía saber cómo sangrar adecuadamente y cómo aplicar ventosas o sanguijuelas. El que los examinadores esperaran que supiera como abrir úlceras y diviesos, así como la forma de
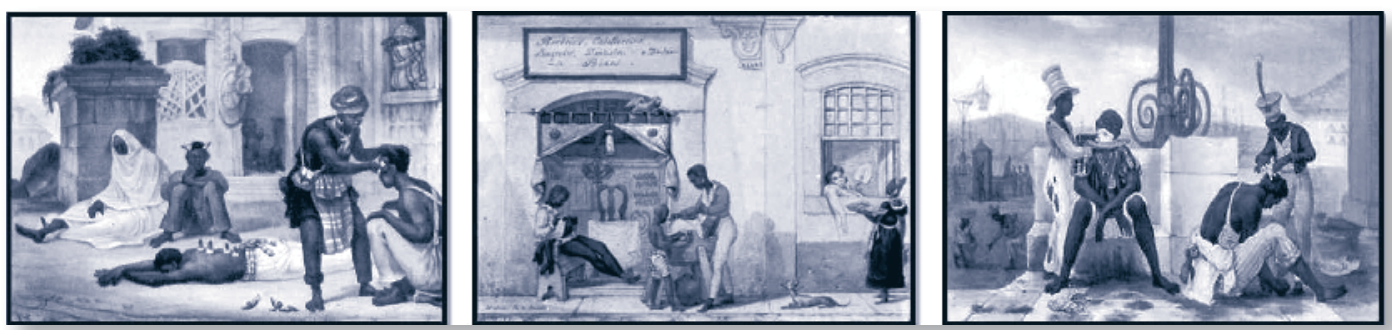

Barberos de color en Brasil, una visión aproximada del mestizaje de estos profesionales en Iberoamérica (Litografías de Jean Baptiste Debret, primera mitad siglo XIX).

Felipe II creó en 1570 el Protomedicato de Indias en México y Lima, sobre el modelo fundado por los Reyes Católicos: Consejo facultativo presidido por un Protomédico con arreglárselas con accidentes y problemas inesperados indica que la ley, como era interpretada, no le confinaba sólo a las sangrías. También se hacían preguntas 
relativas a la extracción de los dientes, particularmente molares. Tras aprobar el examen el barbero prestaba juramento de defender a la Purísima e Inmaculada Concepción. El secretario proporcionaba con detalle una descripción minuciosa del portador, incluyendo no sólo sus rasgos sino también la más mínima cicatriz, a fin de que ningún ladrón pudiera hacer valer este documento como propio ante cualquier funcionario. Cuando el flebotomiano había pasado por todas estas pruebas, pagaba la elevada cuota de 55 pesos y comenzaba su andadura. Para muestra el arancel vigente en México de 1759:

\section{Examen de Flovotomianos:}

"Por el examen de un Flovotomiano percibirá cada uno de los tres Protomédicatos nueve pesos ocho p.s el Promotor Fiscal, tres p.s el Asesor, doce r.s el Mro. Sinodal, diez p.s el Escriv.o tres p.s y seis r.s el Mntro. Egecutor, los dos p.s seis tom.s y seis gran.s del R.l dro. de media anata, que fuera de lo que se deve pagar de su regulación, y entero, y el importe del papel para el titulo, importan las partidas arriba referidas, cincuenta y cinco p.s, seis tom.s y seis gran.s" (Beltrán, 1937).

El sangrador sin licencia practicaba clandestinamente donde no había nadie más para socorrer a la gente a pesar de la Ley que promulgó Felipe II en 1579 en el Pardo y en la que prohibía a los Protomédicos otorgar licencias en las Indias a los barberos que no comparecieran personalmente al examen y se resultaran aprobados [4]. En el Virreinato de Río de la Plata si los infractores eran españoles se les multaba con dinero; y si eran indios, negros o mulatos, les aplicaban cien azotes. Algunas veces, con toda modestia el barbero solicitaba al Real Protomedicato una licencia para practicar abiertamente, utilizando como método el testimonio de aquellos a quienes había salvado o ayudado para hacer ver que el público sufriría si no se le otorgaba dicha licencia. Pero en términos generales, al igual que en la Península se prohibió al barbero sangrar si no tenía la aprobación del Protomedicato. Los protomédicos daban por válido que una cortina y una bacía colgando eran los signos adecuados para un barbero. Decían que, si los sangradores al mismo tiempo exhibían su tradicional celosía y tarjeta, la distinción entre meros peluqueros y barberos, por una parte, y flebotomianos con licencia, por la otra, sería suficiente. A este respecto, Miguel Jose de Azanza, Virrey de Nueva España dispuso el 29 de marzo de 1799, al poco tiempo de llegar al Virreinato que:

"Por quanto se ha dudado si los Barberos están sujetos á sufrir exámen y obtener licencia del Real Tribunal del Protomedicato, y en algunas partes no se les permite exercer su oficio sin que precedan estas formalidades, de lo qual se me ha representado seguirse perjuicio á éstos y también al Público: por tanto he venido en declarar que, con arreglo á las leyes, los Barberos que puramente se exercitan en afeytar ó rasurar de navaja ó tixera, no necesitan de exámen ni de licencia, con tal que se abstengan de sangrar, sacar muelas, echar sanguijuelas ó ventosas, y practicar ninguna de las demás operaciones propias del arte de la Flebotomía, para exercitar el qual debe precisamente preceder la aprobacion y permiso del expresado Real Tribunal. Y porque conviene que los puros Barberos no se confundan con los Sangradores, y el Público no padezca equivocaciones en este punto, mando que los primeros pongan indispensablemente en las puertas de sus tiendas cortina y vacía, y que los segundos distingan las suyas como hasta ahora con celosía y tarjeta; teniendo entendido 
los Barberos, que si se excedieren sangrando ó sacando muelas, el Visitador del Protomedicato procederá contra ellos con arreglo á las leyes. $Y$ para que estas disposiciones lleguen á noticia de todos, ordeno se publiquen en esta Capital y en las demás Ciudades y Villas comprehendidas en el distrito y Virreynato".

Aún así, debido a que muchos barberos sangraban fuera de sus establecimientos, hubo voces en el Nuevo Mundo a fin de que no se hiciese distinción y se examinaran a todos los barberos.

El instrumental empleado no sería distinto del empleado hasta entonces en España, si bien es verdad, que la llegada de los "hierros" para el ejercicio de la Odontología, marca la diferencia técnica entre la ciencia invasora y la autóctona, caracterizada por los procedimientos paliativos y algunas medidas profilácticas. Los pocos instrumentos dejados al morir por dos rapabarbas latinoamericanos también retratan sus rutinas de trabajo:

- Juan de Espinosa. Caracas, año 1636:

"un estuche aforrado en cordován con seis lancetas; una bolsita con herramientas de muelas con seis fierros; una vigornia con su martillo y un rascador y tres botadores de acero".

- Pedro Brito. Guatemala, año 1768:

"un estuche de muelas, un estuche con seis lancetas, otro con tres lancetas, un par de ventosas, una redomita, una jeringa grande, una piedra de afilar, dos fierros de sacar muelas (...) una bigornia con su martillo (yunque de dos puntas para moldear los fierros con el martillo)".

Debido a los excesivos gastos del viaje a la capital donde residía el Tribunal del Protomedicato, junto a las pérdidas que representaba abandonar sus establecimientos durante la ausencia prolongada, se permitió examinar a los flebotomianos en sus propios partidos, con un aumento del costo de 5 pesos entre 20-40 leguas a la redonda de la ciudad de México; 7 pesos y 4 reales entre 40-60 leguas; 10 pesos más de 70 leguas. Esto también permitía la existencia de establecimientos más allá de las murallas, regentados por mestizos y donde atendían a los pobres. Aún así muchos sangradores se ocultaban en las ciudades, entre los puestos de las grandes plazas, allí cortaban barbas, sangraban...

\section{LIBROS PARA LA ENSEÑANZA DEL} ARTE.

Para la enseñanza del arte de la flebotomía propiamente dicha se publicaron diversas obras al margen de los clásicos de la Cirugía como Guido, Saliceto, Lanfranco ... Si bien, no hemos de olvidar que el aprendizaje era más práctico que teórico, pues como ya señalamos, la pasantía al lado de un cirujano aprobado era el recurso más habitual para aquellos que trataban de ejercer como tales barberossangradores tanto a un lado como a otro del Atlántico, aunque ignoramos hasta que punto los aspirantes tenían acceso a estos tratados, pese a que los barberos demostraron ser más cultos de lo esperado. En los inventarios "post mortem" localizados figuran entre otros ítems, libros tocantes a las operaciones de cirugía (Rojo Vega, 1993).

Tampoco sabemos si todos los textos llegaron al Nuevo Mundo pero suponemos que al menos sí lo hicieron los publicados por órdenes religiosas como la de San Juan de Dios cuya presencia y labor fue destacada en América. De cualquier modo, citaremos algunas obras publicadas entre los siglos XVI-XVIII para el estudio de los flebotomianos:

- Sevilla, 1512: Juan de la Cueva publicó su libro Reglas de phlebotomía que tuvo una segunda edición en Salamanca en 1517. 
- Zaragoza, 1533: Juan Lorenzo Carnicer, médico natural de Maella, publicó el libro Versión del francés al español del tratado de flebotomía de Antonio Aviñón que había visto la luz en Sevilla en 1518 con arreglo a los preceptos de la Escuela de Montpellier.

- Burgos, 1547: Tratado muy provechoso de la anatomía y flebotomía de venas y arterias, y de la anatomía de los nervios: con un tratado de ventosas y otro de sanguijuelas, con unas reglas generales para saber los días aptos para las sangrías del Doctor Francisco de Molina (Fernández Valladares, 2004).

- Valladolid, 1557: Coloquio breve y compendioso sobre la materia de la dentadura, y maravillosa obra de la boca de Francisco Martínez de Castrillo escrito en forma de diálogo. Fruto del éxito se hizo una edición posterior en Madrid en 1570 variando el título y estilo de redacción, estructurado como un libro más científico, Tratado breve y compendioso, sobre la maravillosa obra de la boca y dentadura. De este tratado se llegó a publicar una segunda edición en el mismo año y lugar (Martínez Sánchez, 1911). A México llegó en el año 1600 un ejemplar de la obra de Martínez de Castrillo de 1570 sumamente rara de la cual se dice hay únicamente cuatro ejemplares en todo el mundo (Sanfilippo, 1998).

- Tratado de la dentadura, sus enfermedades y remedios. Manuscrito de Juan Bautista Xamarro, napolitano, barbero y sangrador de los pajes la Corona española, que lo dedica el 10 de junio de 1597 a Felipe III siendo éste Príncipe. Parece estar inspirado en la obra del Licenciado Martínez de Castrillo, aunque algunos autores apuntan que se trata de un plagio descarado (Carreras Panchón, 1975b; Sanz Serrulla, 1999). También se le atribuye la autoría de Indicación de la sangría de 1604 publicada en Valladolid.
- Madrid, 1597: Arte de sacar dientes y muelas del que fuera dentista de Felipe II, Miguel Martínez de Leyva. Considerado como "libro fantasma" por algunos historiadores (Carreras Panchón, 1975b) ya que su existencia no se ha podido comprobar.

- Valladolid, 1604: Defensa de las criaturas de tierna edad... de Cristóbal Pérez de Herrera. Trata de la práctica de la sangría, la aplicación de ventosas y cornetillas en lactantes (Ventosa Esquinaldo, 1994).

- Sevilla, 1618: Tratado de Flebotomía de Cristóbal Granado.

- Valencia, 1621: Instrucción de los barberos flobotomianos de Alonso Muñoz, Sangrador Real, Protobarbero y Examinador general de los barberos flebotomianos del Reino. Incluida dentro de la obra de Andrés de Tamayo Tratados Breves de Algebra, y Garrotillo.

- Barcelona, 1627: Tratado breve de Flobotomía de Diego Pérez de Bustos, Sangrador de Cámara y Protobarbero Real, Alcalde y Examinador Mayor de todos los barberos flebotomianos del Reino. Suponemos que tuvo una gran aceptación, pues varias son las ediciones que del mismo se llegaron a publicar en diferentes plazas: Barcelona en $1709 \mathrm{y}$ 1718; Madrid en 1630, 1677 y 1701 y; Valencia en 1700.

- Madrid, 1625: Instrucción de enfermeros escrito por el Enfermero Mayor del Hospital General de Madrid Andrés Fernández y Hermano Mayor de la Mínima Congregación de los Hermanos Enfermeros Pobres fundada por el Venerable Bernardino de Obregón. Si bien es cierto que la primera edición data de 1617 escrita a instancia del fundador de la Congregación, hubo además de esta publicación de 1625, otras posteriores en Zaragoza en 1664 y; Madrid en 1680 y 1728. 


\section{- Directorio de Enfermeros de Simón López} barbero de los hospitales de Castilla. Concluida en 1651, no se llegó a publicar pero hemos querido hacer reseña de esta obra escrita por un barbero.

- Sevilla, 1653: Cuestión en la cual se intenta averiguar cómo, y de que venas, y de que partes se deba sangrar en las enfermedades que curamos escrito por el doctor Pedro de Ahumada. Se trata de una obra confusa, paradigma de la peor medicina del XVII: oscura, farragosa, pretendidamente erudita. Meritoria únicamente por su brevedad, aspira a ilustrar sobre las indicaciones de la flebotomía más que sobre la forma de realizar ésta (Carreras Panchón, 1974).

- Malinas, 1674: Compendio de los tratados de Flobotomía: Capítulo singular y cartapacio de cirujia. Es una recopilación de diferentes autores hecha por el Padre Fray Francisco de la Cruz, Superior de los Hermanos de la Orden de San Juan de Dios.

- Toledo, 1679: Perfecto practicante cirujano y de morbo gálico de Antonio Trilla Muñoz.

- Valencia, 1683: Breve compendio de Cirugía de Fray Matías de Quintanilla, Cirujano mayor del Hospital de Antón Martín de Madrid y General de la Orden de San Juan de Dios. Se publicaron al menos en Valencia, otra edición en 1705.

- Madrid, 1717: Doctrina Moderna para los Sangradores del francés Ricardo Le Preux, Primer Cirujano y Sangrador de la reina María Luisa de Saboya y de los infantes y también Alcalde y Examinador Mayor del Real Protobarberato. Obra de suma aceptación por parte de los flebotomianos, buena prueba de ello son las edicio-
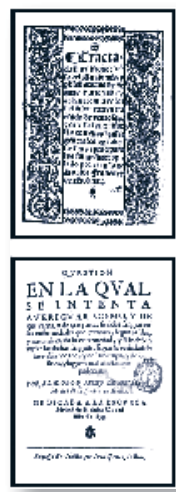

nes que se llegaron a imprimir durante más de un siglo. A saber en Madrid en 1721, 1724, 1741, ¿1760?, 1775, 1778, 1788, 1802, 1825 y 1840 y; Valencia en 1817 y 1822 . Incluso hay autores que señalan su publicación en Salamanca (López Piñero, 1991 y 1992).

- Málaga, 1760: Disertación sobre la sangría memoria presentada a la Academia de Ciencias Naturales y Buenas Letras de Málaga el 15 de noviembre de 1578 por Manuel Fernández Barea quien publicó ese mismo año en Granada Diálogos entre el médico y el Practicante que dedica una pequeña parte a temas relacionados con la boca.

- Madrid, 1764: Tratado odontálgico en el que se exponen las enfermedades de la dentadura, y los medios así manuales como medicinales propios a corregir sus vicios y a conservar su limpieza escrito por Pierre Abadie, Sangrador y Dentista de Carlos III. En 1784 se publicó también en Madrid una segunda edición.

- Madrid, 1794: Tratado Completo de la Flebotomía u operación de la sangría de Juan Fernández Valle, Profesor de Cirugía y segundo Ayudante de Anatomía en el Real Hospital General de Madrid.

- Madrid, 1795: Tratado de las enfermedades de la boca sobre todas las partes del Arte del
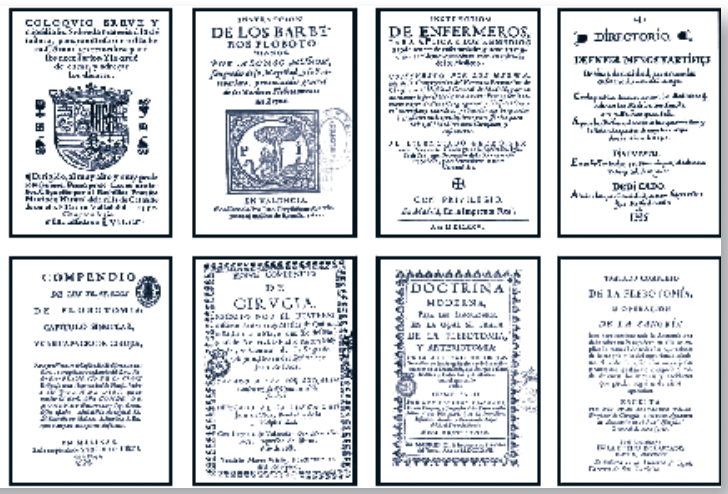

Portadas de las diferentes obras para la enseñanza de los barberos flebotomianos. 
dentista de Francisco Antonio Peláez, Cirujano de la Corte y Dentista de los Reales Hospitales. También fomentó la actividad privada ofreciendo sus servicios en madrileña la calle de Juanelo número 10 (Sanz Serrulla, 2001). Dos años más tarde, se publicaba una segunda edición en Madrid de esta obra de Peláez.

- Madrid, 1799: Tratado de las operaciones que deben practicarse en la dentadura, y método para conservarla en buen estado de Félix Pérez Arroyo, Cirujano Hernista de los Reales Hospitales.

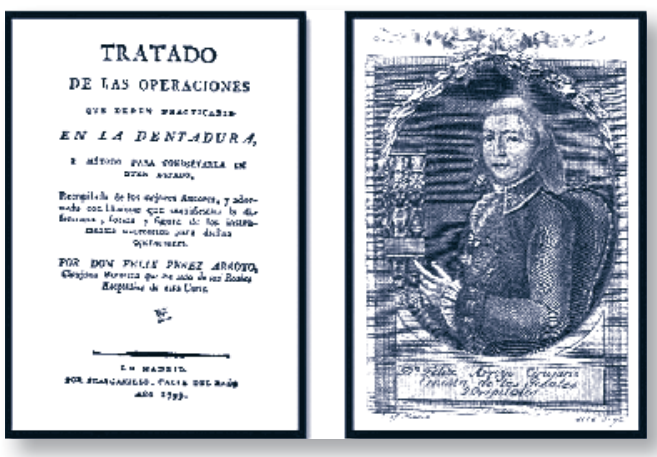

Portada de la obra de Félix Pérez Arroyo que incluye un retrato del autor.barberos flebotomianos.

Sin contar con la edición mejicana del ya mencionado tratado de Le Preux y que fue escrito en 1824 (Sanfilippo, 1998), tan sólo hemos localizado dos títulos que fueron publicados en el siglo XVI en Iberoamérica, también en México y que tal vez pudieron servir como ayuda para el estudio de los sangradores:

- Suma y recopilación de cirugía, con un arte para sangrar muy útil y provechosa del cirujano y enfermero Alonso López de Hinojosos en 1578. Contiene un tratado o capítulo segundo de la sangría artificial donde se define la sangría, se indica la manera más correcta de realizarla y se hacen algunas consideraciones sobre el modo de aplicar ventosas y sanguijuelas. Unas nociones anatómicas sobre la distribución de las venas contribuyen a facilitar la comprensión del texto. En 1595 se publicó en México también una segunda edición aumentada con algunas nociones sobre el reuma.

- Tratado breve de cirugía y del conocimiento y cura de algunas enfermedades que en esta tierra más comúnmente suele haber publicado en 1592. Su autor fue Fray Agustín Farfán, Religioso de la Orden de Santo Agustín y Doctor en Medicina graduado en la Universidad de México.

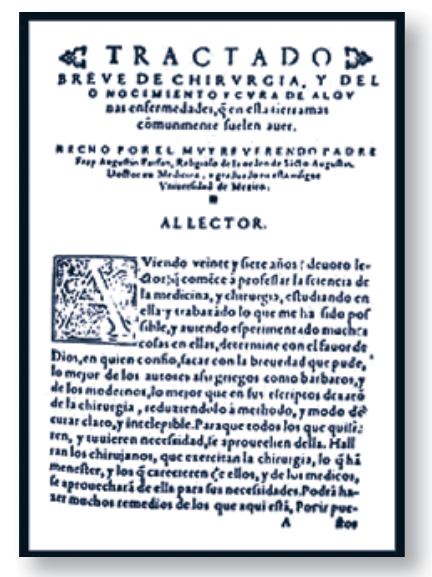

Portada de la obra de Fray Agustín Farfán publicada en México en 1592.

\section{CONCLUSIONES.}

Desde el comienzo de la colonización las cosas funcionaron más bien por inercia... A lo largo de la obra de Saturno Canelón podemos encontrar casos no exentos de controversia, pero en los que se eleva la figura del barbero sangrador como único elemento de curación en muchos casos. Así, describe este autor algunos casos como en 1525, el Ayuntamiento de Ciudad de México contrata a un barbero y cirujano para que ejerza y enseñe el oficio y en 1527 da licencia a otro barbero para atender a los enfermos de bubas. En el Perú, muchos de ellos acompañaban a los ejércitos y, junto a cirujanos, atendían a heridos y fracturados. 
En 1538, el Cabildo limeño había autorizado a un barbero Juan López para "intervenir en cosas de la cirugía, siempre que éstas no fueran de mucha importancia”. Después, ocasionalmente, se dictaban inútiles medidas para reprimir el ejercicio ilegal; una de ellas decretó que siendo los barberos quienes curaban, antes de hacerlo, debían mostrar sus títulos. Como contrapartida, en Huamanga en 1552 a falta de médico, un barbero recibió licencia para ejercer como tal. En 1604, en Córdoba, un barbero fue licenciado para ejercer como médico en el hospital; en 1610 se graduó el primer galeno en Buenos Aires, pero dos años después, al único barbero-cirujano allí existente le prohibieron irse a Brasil y le asignaron una remuneración. Entre 1620 y 1622, durante la epidemia de viruela, no hubo médico en Buenos Aires. Al único representante del arte de curar residente en Guayaquil en 1636 - un barbero sangrador - también debieron suplicarle que se quedara. Durante la primera mitad del siglo, los médicos y cirujanos en toda Centroamérica no pasaron de doce... A lo largo del siglo XVII aparecen dos referencias a la práctica de un maestro barbero en el hospital San Alexo de Guatemala. El informe de la autopsia realizada por un barbero, el cual denotaba una buena base de conocimientos anatómicos y fisiológicos...

Durante el siglo XVIII los barberos indígenas quiteños adquirieron notable nombradía: uno de ellos, Juan Coronado, conquistó por concurso, el cargo de Maestro Mayor y fue encomiado por el Protomédico Bentboll; Blas Huatimpas fue ensalzado como un gran estudioso, y hasta tenido como un santo. Los científicos españoles Antonio Ulloa y Jorge Juan destacaron el prestigio y destreza de estos prácticos, y además, describieron su llamativa indumentaria: camisa bordada, pantalones blancos de extremos bordados y zapatos con hebillas de plata...

Concluimos por tanto que dada la escasez de médicos y cirujanos en las colonias, la figura del barbero-sangrador se convirtió en un elemento esencial en la medicina colonial pues tuvo una gran actividad, siendo - como ya se ha señalado previamente - en muchos casos el único referente al que acudir en caso de enfermedad, además de introducir la Odontología en el Nuevo Mundo y que a la postre daría lugar a la escisión de estos Cirujanos-Sangradores para convertirse más tarde en CirujanosDentistas.

\section{BIBLIOGRAFÍA.}

- Aliaga Pérez, A. et al (2005): Del arte de curar en los tiempos de Don Quijote (médicos, cirujanos, barberos y similares). ACV Ediciones, Barcelona.

- Alvárez-Sierra, J. (1961): Historia de la cirugía española, con diccionario biobibliográfico de cirujanos españoles, hispanoamericanos y filipinos. Diana, Artes Gráficas, Madrid.

- Amezcua Martínez, M. (1997): Barberos y sangradores flebotomianos en Granada: norma y sociedad en los siglos XVII y XVIII. Cultura de los Cuidados 1, 31-36.

- Arribas Martín, J. M. (2005): Breve compendio de cirugía de Matías de Quintanilla O. H. Archivo Hospitalario. Revista de Historia de la Orden de San Juan de Dios, 3, 571-575.

- Astrain Gallart, M. (1996): Barberos, cirujanos y gente de mar. La sanidad naval y la profesión quirúrgica en la España ilustrada. Ministerio de Defensa, Madrid.

- Barceló Serra, P. (1991): Historia de la Odontoestomatología Balear 1875-1936. Universidad Complutense de Madrid, Madrid.

- Beltrán, J. R. (1937): Historia del Protomedicato de Buenos Aires. El Ateneo, Buenos Aires.

- Carreras Panchón, A. (1974): Las actividades de los barberos durante los siglos XVI al XVIII. Cuadernos de Historia de la Medicina Española, 13, 205-218. 
- Carreras Panchón, A. (1975a): Enfermeros y barberos en el siglo XVII según el manuscrito de Simón López. En Actas del IV Congreso Español de Historia de la Medicina, Granada 24-26 de abril de 1973, Secretariado de Publicaciones de la Universidad de Granada-Obra Cultural de la Caja de Ahorros de Granada, Granada, Tomo III, pp 247-250.

- Carreras Panchón, A. (1975b): La Odontología en España durante los siglos XVI y XVII. Cuadernos de Historia de la Medicina Española, 14, 43-54.

- Cifuentes i Comamala, L. (2000): La medicina en las galeras de la Corona de Aragón a finales de la Edad Media: la caja del barbero y sus libros. Medicina \& Historia. Revista de Estudios Históricos de las Ciencias Médicas, 4, $1-15$.

- Donahue, M. P. (1985): Historia de la Enfermería. Ediciones Doyma, Barcelona.

- Eseverri Chaverri, C. (1995): Historia de la Enfermería Española e Hispanoamericana. Universitas, Madrid.

- Fernández Valladares, M. (2004): Otro libro para maese Nicolás: un raro tratado de flebotomía para barberos impreso en Burgos como librito de cordel. En Siglos dorados: homenaje a Agustín Redondo, (Civil, P. coord.), Editorial Castalia, Madrid, Tomo I, pp 435-447.

- Fernández Valladares, M. (2005): La imprenta en Burgos (1501-1600). Arco/Libros, S. L., Madrid, Volumen I.

- García Ballester, L. (2001): La búsqueda de la salud. Sanadores y enfermos en la España medieval. Península, Barcelona.

- García Martínez, A. C., et al: (1993): Presentación y análisis de la obra "Instrucción de enfermeros de Andrés Fernández", 1625. Aproximación a la Enfermería española de los siglos XVI-XVII. Consejo General de Colegios de Diplomados en Enfermería de España, Madrid.

- Jamieson, E. M., Sewall, M. F. y Suhrie, E. B. (1968): Historia de la Enfermería. Interamericana, México.

- Laín Entralgo, P. (1971): Historia Universal de la Medicina. Salvat Editores, S. A. Barcelona, Tomo I.

- Lanning, J. T. (1997): El Real Protomedicato. La Reglamentación de la profesión médica en el Imperio Español. Traducción Miriam de los Ángeles Díaz Córdoba-José Luis Fernández Soberanes. Facultad de Medicina-Insti- tuto de Investigaciones Jurídicas de la Universidad Nacional Autónoma de México, México.

- López Acuña, A. (1952): Una curiosa profesión liberal en el siglo XVIII. Barberos sangradores y Cirujanos. Boletín de la Comisión Provincial de Monumentos Históricos y Artísticos de Lugo, 36, 292-295.

- López Piñero, J. M. et al (1987): Bibliographia médica hispánica 1475-1950. Instituto de Estudios Documentales e Históricos sobre la Ciencia. Universidad de Valencia-CSIC, Valencia. Volumen I: Libros y Folletos, 1475-1600.

- López Piñero, J. M. et al (1989): Bibliographia médica hispánica 1475-1950. Instituto de Estudios Documentales e Históricos sobre la Ciencia. Universidad de Valencia-CSIC, Valencia. Volumen II: Libros y Folletos, 1601-1700.

- López Piñero, J. M. et al (1991): Bibliographia médica hispánica 1475-1950. Instituto de Estudios Documentales e Históricos sobre la Ciencia. Universidad de Valencia-CSIC, Valencia. Volumen IV: Libros y Folletos, 1801-1850.

- López Piñero, J. M. et al (1992): Bibliographia médica hispánica 1475-1950. Instituto de Estudios Documentales e Históricos sobre la Ciencia. Universidad de Valencia-CSIC, Valencia. Volumen III: Libros y Folletos, 1701-1800.

- Loste Echeto, L. (1948): Estatutos de la Primitiva Cofradía de Médicos, Boticarios y Cirujanos de Huesca (Siglo XV). Medicamenta. Revista de Estudios y Trabajos Profesionales de Ciencias Médicas, 152, 109-111.

- Martín Santos, L. (2000): Barberos y Cirujanos de los siglos XVI y XVII. Consejería de Educación y Cultura de la Junta de Castilla y León, Salamanca.

- Martínez Sánchez, J. (1911): Bibliografía de la Odontología Española. Índice para formar un catálogo razonado, de las obras impresas en castellano que tratan sobre el Arte del Dentista. Imprenta de La Odontología, Madrid. - Moll, A. A. (1944): Aesculapius in Latin America. W. B. Saunders Company, Philadelphia.

- Parrilla Hermida, M. (1975): Ricardo Lepreux y su manual para los sangradores. Medicina Española, 74, 183188. 
- Rodríguez Perales, R. M. (2006): Aportaciones didácticas de un tratado para practicantes escrito en el siglo XVII: "Compendio de los tratados de flobotomía: capítulo singular y cartapacio de cirujía”. Archivo Hospitalario. Revista de Historia de la Orden de San Juan de Dios, 4, 455-473.

- Rojo Vega, A. (1993): Enfermos y sanadores en la Castilla del siglo XVI. Secretariado de Publicaciones. Universidad de Valladolid, Valladolid.

- Sanfilippo, B, J. (1998): Antes de hace veinticinco años o en dónde se enseñaba la odontología en México. Revista ADM, Órgano Oficial de la Asociación Dental Mexicana-Federación Nacional de Colegios de Cirujanos Dentistas A.C., 3, 150-156.

- Sanz Serrulla, J. (1999): Historia General de la Odontología Española. Masson, S. A., Barcelona.

- Sanz Serrulla, J. (2001): Diccionario histórico de dentistas españoles. Acción Médica, S. A. Madrid.

- Saturno Canelón, J. (1996): Barberos y sucesores. Medio milenio de Odontología en Iberoamérica. Monte Ávila Editores, Caracas.

- Ventosa Esquinaldo, F. (1994): La profesionalización de los cuidados en España. Los manuales de técnicas. Índex de Enfermería, 8-9, 9-14.

- Ventosa Esquinaldo, F. (2000): Barbero-sangrador-flebotomiano. Híades. Revista de Historia de la Enfermería, 7, 209-217.

\section{REPERTORIOS LEGISLATIVOS.}

- Bando del virrey Azanza, México, 29 de marzo de 1799.

- El Fuero Real de España. Madrid, 1781. Oficina de Pantaleón Aznar, Tomo II.

- Fuero Juzgo en latín y castellano. Madrid, 1815. Ibarra, Impresor de Cámara de S. M.

- Las Siete Partidas del Rey Don Alfonso El Sabio. Madrid, 1807. Imprenta Real, Tomo III.

- Leyes de Recopilación. Madrid, 1775. Imprenta de Pedro Marín, Tomo I.

- Novísima Recopilación de las Leyes de España. Madrid, 1805. Imprenta de Sancha. Tomos IV-V.

- Recopilación de las Leyes de los Reynos de las Indias. Imprenta de Julián de Paredes. Madrid, 1681. Tomo II.

\section{NOTAS.}

[1] Con el transcurso del tiempo el Tribunal del Protobarberato pasó a formar parte del Protomedicato hasta su completa desaparición mediante una Real Cédula de Carlos III de 13 de abril de 1780: "Gobernada la Cirugía por sus propios facultativos, reunirá en sí el exámen y aprobación de sangradores, y el conocimiento de todas las cosas, que hasta aquí haya concedido el Tribunal del Protobarberato, quedando éste suprimido en todas sus partes".

[2] Acerca de la limpieza de sangre los Reyes Católicos en Granada promulgaron por pragmática de 30 de septiembre de 1501 la siguiente ley: "Mandamos, que los reconciliados por el delito de la heregía, y apostasía, ni los hijos y nietos de quemados y condenados por el dicho delito hasta la segunda generación por línea masculina, y hasta la primera por línea femenina, no puedan ser ni sean del nuestro Consejo, ni Oidores de las nuestras Audiencias...ni Físico ni Cirujano, ni Boticario, ni tener otro oficio público, ni Real en alguna de las ciudades, y villas y lugares de los nuestros Reynos, y Señoríos...”.

[3] Traducido al castellano de Moll: "Inadaptados del Viejo Mundo, fracasados, ansiosos de probar en un nuevo campo, insatisfechas mediocridades, aventureros, piadosos hombres de Dios, un ocasional degollador o criminal, y aquí y allá un hombre de ciencia y puede que hasta un genio, de todo había entre los tempranos practicantes atraídos a América por la esperanza de mejorar su suerte, si no ganando riquezas, haciéndose un nombre".

[4] "MANDAMOS, Que los Protomédicos no dén licencia en las Indias á ningún Médico, Cirujano, Boticario, Barbero, Algebrifta, ni á los demás, que exerce la Facultad de Medicina, y de Cirugia, fi no parecieren perfonalmente ante ellos á fer examinados, y los hallaren habiles y suficientes para vfar, y exercer...”. 